\title{
Natural compound rhein suppresses colorectal cancer cells growth through mTOR/p70S6 kinase pathway in vitro and in vivo
}

Haibo Zhang

Kyungpook National University

Song Park

Daegu Gyeongbuk Institute of Science and Technology

Hai Huang

Kyungpook National University

Jun koo Yi

Geyongbuk livestock research institute

Sijun Park

Kyungpook National University

Wookbong Kwon

Daegu Gyeongbuk Institute of Science and Technology

Eungyung Kim

Kyungpook National University

Soyoung Jang

Kyungpook National University

Siyong Kim

Kyungpook National University

Seongkyoon Choi

Daegu Gyeongbuk Institute of Science and Technology

\section{Sung-Hyun Kim}

korea polytechnic college

Kangdong Liu

China -US(Henan) Hormel Cancer Institute

\section{Zigang Dong}

China-US(Henan) Hormel Cancer Institute

\section{Zae Young Ryoo}

Kyungpook National University

Myoung Ok Kim ( $D$ ok4325@knu.ac.kr)

Kyungpook National University 
Research

Keywords: Rhein, mTOR, p70S6 kinase, xenograft, colorectal cancer

Posted Date: July 14th, 2020

DOI: https://doi.org/10.21203/rs.3.rs-41306/v1

License: (c) (i) This work is licensed under a Creative Commons Attribution 4.0 International License. Read Full License 


\section{Abstract}

Background: Rhein is a natural agent isolated from the traditional Chinese medicine rhubarb, which has been used as a medicine in China since ancient times. Although rhein was found to have significant anticancer effects in different cancer models, the effect and the underlying mechanisms of action of rhein in colorectal cancer (CRC) remain unclear. The mTOR/p70S6 kinase (p70S6K) pathway has been demonstrated as an attractive target for developing novel cancer therapeutics.

Methods: The human CRC cell lines HCT116, HCT15, and DLD1 and xenograft mice were used in this study to investigate the effects of rhein. Assessments of cellular morphology, cell proliferation, and anchorage-independent colony formation were performed to examine the effects of rhein on cell growth. Wound healing assay and transwell migration and invasion assay were conducted to detect cell migration and invasion. Cell cycle and apoptosis were investigated by flow cytometry and verified by immunoblotting. Tissue microarray was used to detect mTOR expression in patients with CRC. Gene overexpression and knockdown were implemented to analyze the function of mTOR in CRC. The in vivo effect of rhein was assessed in a xenograft mouse model.

Results: Rhein significantly inhibited CRC cell growth by inducing S phase cell cycle arrest and apoptosis. It also inhibited CRC cell migration and invasion ability through EMT process. mTOR was highly expression in CRC cancer tissues and cells exhibited high mTOR expression. Overexpression of mTOR promoted cell growth, migration, and invasion ability, whereas mTOR knockdown diminished these phenomena of CRC cells in vitro. Moreover, rhein directly targeted mTOR and suppressed the mTOR/p70S6K signaling pathway in CRC cells. Intraperitoneal administration of rhein inhibited CRC cell HCT116 xenograft tumor growth through the mTOR/p70S6K pathway.

Conclusions: Rhein exerted anticancer activity in vitro and in vivo through directly targeting mTOR and inhibiting mTOR/p70S6K signaling pathway. These data indicate that rhein is a potent anticancer agent that could be useful for the prevention or treatment of CRC.

\section{Background}

Colorectal cancer (CRC) is the third most common diagnosed and second leading cause of cancer-related death among men and women combined in the United States [1]. The incidence and mortality of CRC has been steadily rising globally. Surgery still remains the most effective treatment option for CRC, but the risk of recurrence is high. Therefore, there is still an urgent need to develop more effective chemotherapy for $\mathrm{CRC}$ treatment.

The progression of CRC is accompanied by gene mutations and abnormal expression [2, 3]. $\mathrm{PI} 3 \mathrm{~K} / \mathrm{Akt} / \mathrm{mTOR}$ pathway was commonly deregulated in human cancer. mTOR was considered as a major regulator of this signaling pathway, which regulates multiple biological processes, including ribosome biogenesis, mRNA translation, cell proliferation, autophagy, and inflammation [4]. Deregulation of mTOR signaling is associated with the development of obesity, type 2 diabetes, and cancer [5]. In 
recent years, targeting the mTOR signaling has generated significant interest for cancer therapy [6]. In $\mathrm{CRC}$, tandutinib was reported to inhibit colon cancer growth by suppressing Akt/mTOR signaling pathway [7]. Tunicamycin was found to inhibit the growth and aggressiveness of colon cancer cells through down regulation mTOR expression [8]. Inositol-6 phosphate induces autophagy of HT29 colon cancer cells by inhibiting the Akt/mTOR pathway [9]. These results indicated that targeting mTOR is a promising strategy for developing novel cancer therapeutics.

Natural compounds are the major resources of drug development. Rhein (4, 5-dihydroxyanthraquinone-2carboxylic acid) is a natural anthraquinone found in several medicinal plants, including Rheum palmatum, Polygonum multiflorum, Aloe barbadensis, and Cassia tora [10]. A previous study suggested that rhein strongly inhibited non-small-cell lung cancer cells growth in vitro and in vivo by suppressing STAT3 pathway [11]. Rhein also induced HepaRG cell death via S phase cell cycle arrest and increased apoptosis [12]. In addition, the anticancer activity of rhein has been reported in breast cancer [13, 14], ovarian cancer [15, 16], and colon cancer [17], suggesting that it could be a novel agent for the prevention and treatment of CRC.

Although previous studies suggest that rhein exerts potent anticancer ability, the direct target proteins of rhein in CRC have not been identified. In the present study, we investigated the anticancer effects of rhein in CRC using in vitro and in vivo experiments and found that rhein suppressed CRC cell growth by directly targeting and inhibiting the mTOR/p70S6K pathway. Our results revealed that rhein might be a potential candidate for CRC treatment.

\section{Materials And Methods}

\section{Reagents and antibodies}

Rhein (purity: >98\% assessed by HPLC) was purchased from Harvey Biotech Co., Ltd (Beijing, China). For in vitro experiments, rhein was dissolved in dimethyl sulfoxide (DMSO, Fisher Scientific). CNBr Sepharose 4B beads were obtained from GE Healthcare (NJ, USA). The primary antibodies PI3K (p85, Cat\# 4257), phosphorylated Akt (Ser473, Cat\# 9271), total Akt (Cat\# 9272, phosphorylated mTOR (Ser2448, Cat\# 2971s), total mTOR (Cat\# 2972s), total mTOR (Cat\# 2983), Cleaved caspase3 (Asp175, Cat\# 9661), phosphorylated p53(Ser15, Cat\# 9284), Bax (Cat\# 2772s) , p70 S6 Kinase (Cat\# 9202), phospho-p70 S6 kinase (Thr389, Cat\# 9234), p53 (Cat\# 2527), CDK4 ( Cat\# 12790), CDK2 (Cat\# 2546), Cyclin E1(Cat\# 20808), E-cadherin (Cat\# 3195), N-cadherin (Cat\# 4061), HSP90 (Cat\# 4874), 4EBP1 (Cat\# 9644), phospho-4EBP1 (Ser65, Cat\# 9451), GSK3 3 (Cat\# 9315), and phospho-GSK3ß (Ser9, Cat\# 9322) were purchased from Cell Signaling Technology (Beverly, MA, USA). $\beta$-Actin (Cat\# sc47778), HSF1 (Cat\# sc130164), Cyclin A1 (Cat\# sc751) were purchased from Santa Cruz Biotechnology (Santa Cruz, CA, USA). Ki67(Cat\# ab15580), Vimentin (Cat\# ab92547) were purchased from Abcam company (USA).

\section{Cell culture}


The human CRC cell lines HCT15, HCT116, DLD1, HT29, SW620 and normal human colon epithelial cells CCD-18Co were purchased from ATCC. HCT116 and HT29 cells were cultured in McCoy's 5A medium. SW620 cells were cultured in L15 medium (Leibovitz). HCT15 and DLD1 were cultured in RPMI1640 medium. CCD-18Co cells were cultured in MEM medium (Leibovitz). All medium was supplemented with $10 \%$ FBS (Gibco) and $1 \%$ antibiotics. All cells were incubated at $37^{\circ} \mathrm{C}$ in a $5 \% \mathrm{CO}_{2}$ humidified incubator.

\section{CCK-8 assay}

CRC cells were plated on 96-well plates $\left(1 \times 10^{3}\right.$ cells / well) to allow attachment and incubated overnight and then treated with various concentrations of rhein or DMSO for $2,24,48,72$, and $96 \mathrm{~h}$, followed by incubated with $10 \mu \mathrm{l} \mathrm{CCK-8} \mathrm{solution} \mathrm{(Dojindo} \mathrm{Japan)} \mathrm{per} \mathrm{well} \mathrm{for} \mathrm{an} \mathrm{additional} 1 \mathrm{~h}$ at $37^{\circ} \mathrm{C}$ in a $5 \% \mathrm{CO}_{2}$ incubator. The absorbance at $450 \mathrm{~nm}$ was assessed using a spectrophotometer (BioTek).

\section{Anchorage-independent cell growth}

CRC cells $\left(8 \times 10^{3}\right.$ cells/well) seeded into complete growth medium containing $0.3 \%$ agar with various concentrations of rhein, then overlaid into 6 well plate containing $0.6 \%$ agar base and various concentrations of rhein. Plates were incubated at $37^{\circ} \mathrm{C}$ in a $5 \% \mathrm{CO}_{2}$ incubator for 2 weeks, then take photographs under microscope (Leica) and count colonies using ImageJ software.

\section{Cell cycle and apoptosis analysis}

CRC cells were seeded in $60-\mathrm{mm}$ culture dishes $\left(2 \times 10^{5}\right.$ cells/dish). After incubated for $12 \mathrm{~h}$, cells were then treated with various concentrations of rhein for $48 \mathrm{~h}$. For cell cycle assay, cells were collected and fixed in $70 \%$ cold ethanol and stored at $-20^{\circ} \mathrm{C}$ overnight. Cells were dyed using RNase $(100 \mu \mathrm{g} / \mathrm{ml})$ and propidium iodide $(\mathrm{Pl}, 20 \mu \mathrm{g} / \mathrm{ml})$ staining buffer. For apoptosis assay, cells were collected and then dyed using Annexin V (BioLegnd, USA) and PI. The cell cycle and apoptosis were analyzed by flow cytometry (FACSCalibur; BD Science, California, USA).

\section{Wound-healing assay}

The migration ability of the CRC cells was evaluated by wound healing assays. When cells grew to $90 \%$ confluence in 6-well dishes, a scratch was then created by scratching the monolayer with a $200 \mu$ plastic pipette tip. Thereafter, treated various concentrations of rhein to the cells for $24 \mathrm{~h}$. This was followed by microscopic examination of the cells at the time 0,12 , and $24 \mathrm{~h}$. The remaining wound area was calculated using the ImageJ software (v. 4) program.

\section{Invasion and migration assays}

Matrigel migration assay was performed in transwell plates (Corning) according to the manufacturer's instructions. The lower compartment was filled with $700 \mu$ medium containing $10 \%$ FBS. Samples containing $8 \times 10^{4}$ cells in $100 \mu \mathrm{l}$ medium containing $1 \%$ FBS were added to the upper chamber, $12 \mathrm{~h}$ later treat different concentrations of rhein in upper chamber. After $48 \mathrm{~h}$, cells were fixed with methanol for 15 
min, the noninvasive cells were removal using a cotton swab. The invaded cells were stained with $0.1 \%$ crystal violet. For invasion assays, the chamber was pre-coated with Matrigel and $8 \times 10^{4}$ cells were plated onto the upper chamber. The other procedures were performed in the same manner as done for the migration assay. The invaded cell numbers were quantified by counting the stained cells under a microscope.

\section{In vitro pull-down assay}

To verify the interaction between rhein and mTOR, HCT116 and HCT15 cell lysates $(500 \mu \mathrm{g})$ were incubated with Sepharose 4B, or rhein-Sepharose 4B beads in a reaction buffer $(150 \mathrm{mM} \mathrm{NaCl}, 50 \mathrm{mM}$ Tris $\mathrm{pH} 7.5,5 \mathrm{mM}$ EDTA, $0.01 \% \mathrm{NP} 40,1 \mathrm{mM}$ DTT, $2 \mu \mathrm{g} / \mathrm{ml} \mathrm{BSA}$ ). After gentle rocking overnight at $4{ }^{\circ} \mathrm{C}$, the beads were washed five times with washing buffer ( $50 \mathrm{mM}$ Tris pH 7.5, $5 \mathrm{mM}$ EDTA, $150 \mathrm{mM} \mathrm{NaCl}, 1 \mathrm{mM}$ DTT, $0.01 \%$ NP40) and binding was visualized by Western blot analysis.

\section{Quantitative real-time PCR}

RNAs were extracted using TRIzol reagent (Invitrogen), and reverse transcription was performed using the First Strand cDNA Synthesis Kit (Takara Bio, Shiga, Japan). Quantitative real-time PCR was conducted with SYBR green (Takara Bio) using the StepOnePlus Real-Time PCR system (Applied Biosystems, Foster City, CA). $\beta$-Actin was served as reference gene. The relative gene expression was calculated using the $2^{-\triangle \Delta C t}$ method. The primer sequences used were as follows: HSF, forward 5'-ACCCA

TGCTTCCTGCGTGGC -3', reverse 5'-TGCTTCTGCCGAAGGCTGGC -3'; HSP90, forward 5'TTCAGACAGAGCCAAGGTGC-3', reverse 5'-CAATGACATCAACTG

GGCAAT-3'; LDHA, forward 5'-TGGAGTGGAATGAATGTTGC-3', reverse 5'-ATAGCCCAGGATGTGTAGCC-3'; and $\beta$-Actin, forward 5'-AGCGAGTATCCCCCA

AAGTT-3', reverse 5'- GGGCACGAAGGCTCATCATT-3'.

\section{Establishment of stable mTOR overexpression cell lines}

pcDNA3-Flag mTOR wt as a gift obtained from Jie Chen (Addgene \# 26603) [18], empty vector (pcDNA3.1) was purchased from Invitrogen (V79020). For transfection experiments, FuGENE HD transfection reagent (Promega) were used following the manufacturer's instructions. For stable transfection, cells were treated with $600 \mu \mathrm{g} / \mathrm{ml}$ of G418 (Gibco) for 2 weeks. Individual G418 resistant cells were maintained in the presence of G418.

\section{Lentiviral production and infection}

The lentiviral mTOR shRNA vectors (sh-mTOR\#2 sequence: 5'-CCGGCCTGGCAAC 
GTCAAAGAAGGGTTGCTTTTTG-3') for the knockdown of mTOR were purchased from Sigma. 293T cells were co-transfected with pLKO.1-mock or pLKO.1-sh-mTOR and pMDLg/pRRE, pMD2.G, and pRSV-Rev using FuGENE HD transfection reagent (Promega). The HCT116 and HCT15 cells were infected with lentivirus together with $8 \mu \mathrm{g} / \mathrm{mL}$ polybrene (Sigma). After $48 \mathrm{~h}$, the cells were treated with puromycin (2 $\mu \mathrm{g} / \mathrm{ml}$ ) for 4 days, thus establishing a stable knockdown of mTOR in the HCT116 and HCT15 cell lines.

\section{Western blotting assay}

Protein extraction from cells and tumor tissues were performed using the Pro-Prep lysis buffer (Intron Biotechnology, Korea). Protein obtained from lysates were separated by SDS-PAGE and then transferred onto polyvinylidene difluoride membranes. The membranes were incubated overnight with the primary antibodies at $4^{\circ} \mathrm{C}$. Subsequently, the membranes were incubated with corresponding secondary antibodies for $1 \mathrm{~h}$ at room temperature. Immunoblots were visualized using ECL detection kit (GE Healthcare, Seoul, Korea) by Davinch imaging system (Davinch-K, Seoul, Korea).

\section{Immunofluorescence analysis}

CRC cells were seeded in 2 well plates, and then treated with various concentrations rhein for $48 \mathrm{~h}$. Then the cells were fixed in $4 \%$ formaldehyde for 15 min, permeabilized with $0.3 \%$ Triton X-100, and incubated with mTOR antibody (1:500; Cat \# $2983 \mathrm{CST}$ ) overnight at $4{ }^{\circ} \mathrm{C}$. The secondary antibody Alexa Fluor 488conjugated goat anti-rabbit IgG antibody (Invitrogen) was incubated with cells at room temperature for 1 $\mathrm{h}$ in the dark. The nuclei were stained with 4', 6-diamidino-2-phenylindole (DAPI). Representative images were captured using a fluorescence microscope (Leica).

\section{In vivo xenografts experiments}

All animal experiments were performed according to the guidelines and approval of Kyungpook National University. HCT116 cells ( $1 \times 10^{7}$ cells) suspended in $200 \mu \mathrm{L}$ PBS were injected subcutaneously in the flank of Balb/c athymic nude mice (male, aged 4-6 weeks). After 6 days of implantation, mice were divided into three groups consisting of eight mice per group. Two groups were treated with rhein at 10 or $50 \mathrm{mg} / \mathrm{kg}$ body weight (dissolved in 5\% DMSO and 10\% Tween-20 in PBS), and the third group was treated with vehicle only. Rhein or vehicle was intraperitoneally injected three times a week for 32 days. Tumor volume and body weights were measured every 4 days. Tumor volume was calculated using the following ellipsoid formula: tumor volume $\left(\mathrm{mm}^{3}\right)$ (length $\times$ width $\times$ height $\times 0.52$ ).

\section{Immunohistochemical staining}

The tumor tissues sections were baked at $60^{\circ} \mathrm{C}$ overnight, rehydrated with xylene and graded alcohols, then antigen-retrieved by heat treatment in citrate buffer $(\mathrm{pH} 6.0)$. Primary antibodies were incubated overnight at $4^{\circ} \mathrm{C}$ (Ki-67, 1:200; Cyclin D1, 1:200; HSF1, 1:100; Cyclin A1, 1:200). Then incubated with 
biotin-conjugated secondary antibody for $1 \mathrm{~h}$ at $37^{\circ} \mathrm{C}$. Images were visualized by a microscope and analyzed using the ImageJ software (v. 4) program.

\section{Statistical analysis}

All data were presented as mean \pm SD from at least three independent experiments. Statistical significance was determined using the Student's t-test. A $p$ value $<0.05$ was considered to be statistically significant.

\section{Results}

\section{Rhein exhibits antiproliferative effects in CRC cells}

To determine the effect of rhein on CRC cell growth, HCT116, HCT15, and DLD1 cells were used. These CRC cells were treated with various concentrations of rhein $(0,10,20,40$, and $60 \mu \mathrm{M})$ for $24 \mathrm{~h}$. At the concentration of $40 \mu \mathrm{M}$, there was an obvious cell death accompanied by morphological changes such as round-shaped and transparent in CRC cells (Fig. 1a). These changes in the CRC cells morphology may be due to the inhibition of cell growth and induction of apoptosis. Furthermore, whether rhein was toxic to the normal colon epithelial cells CCD-18Co was examined, and the results demonstrated that the tested concentrations of rhein did not significantly inhibition the growth of CCD-18Co cells (Fig. 1b). Next, we evaluated the half-maximal inhibitory concentration (IC50) of rhein in HCT116, HCT15, and DLD1 cells, and the IC50 values were found to be $43.39 \mu \mathrm{M}, 46.08 \mu \mathrm{M}$, and $36.33 \mu \mathrm{M}$, respectively in these cells at 24 h (Fig. 1c); hence, a concentration of $40 \mu \mathrm{M}$ was chosen for subsequent experiments. The CCK-8 assay results indicated that the proliferation of HCT116, HCT15, and DLD1 cells were significantly inhibited in a dose-and time-dependent manners (Fig. 1d). Results of the anchorage-independent colony formation assay revealed a significant decrease in the colony number with rhein treatment in CRC cell lines (Fig. 1e, f). Collectively, rhein effectively inhibited CRC cells growth and presented less cytotoxic to the normal colon epithelial cells.

\section{Rhein inhibits the migration and invasion of CRC cells}

Cancer metastasis causes the majority of patient deaths from solid tumors [19]. To determine whether rhein could inhibit the migration and invasion of CRC cells, we firstly examined the effect of rhein on the motility of CRC cells using a wound healing assay. The HCT116, HCT15, and DLD1 cells were treated with rhein at $0,10,20$, and $40 \mu \mathrm{M}$ for $0-24 \mathrm{~h}$. Results demonstrated CRC cells healing over scratch was inhibited by the treatment of rhein in HCT116, HCT15 and DLD1 cells compared to that in control cells at 12 or $24 \mathrm{~h}$ (Fig. 2a, b). Next, the effect of rhein on CRC cells migration and invasion was measured by transwell assay. After treatment with rhein (at $0,10,20$, or $40 \mu \mathrm{M})$ for $48 \mathrm{~h}$, the number of migrated or invaded cells were significantly decreased in a dose-dependent manner (Fig. 2c-f). Moreover, the migration and invasion of tumor cells were closely related to the epithelial-mesenchymal transition (EMT). To determine the role of rhein in the EMT process, we examined the EMT-related proteins including E-cadherin, N-cadherin, and vimentin using western blot assays. As expected, treatment with rhein 
upregulated the expression of E-cadherin and downregulated the expression of $\mathrm{N}$-cadherin and vimentin (Fig. 2g). These finding suggested that rhein significantly inhibited CRC cells migration and invasion by regulating the expression of EMT-related proteins.

\section{Rhein induces cell cycle S phase arrest and apoptosis of CRC cells}

To further explore the mechanism of rhein on the proliferation of CRC cells, we investigated the cell cycle distribution after $48 \mathrm{~h}$ treatment with rhein by flow cytometry assays. Results indicated that rhein treatment markedly increased cell number of CRC cells in S phases (Fig. 3a, b). To confirm this change, we examined the levels of $S$ phase regulatory proteins by western blotting. Results showed that rhein treatment significantly decreased the expressions of Cyclin A1, Cyclin E1, and CDK2 in HCT15 and HCT116 cells (Fig. 3c). The mTOR pathway has been reported to regulate the translation of Cyclin D1 [20,

21], and hence we examined whether rhein treatment can influence the expression of Cyclin D1 and found that the expression of Cyclin D1 was downregulated (Fig. 3c). These results suggested that rhein effectively induced $S$ phase cell cycle arrest by inhibiting the expressions of Cyclin A1, Cyclin E1, CDK2 and Cyclin D1. We next examined whether rhein induces apoptosis of CRC cells using Annexin V/PI staining and flow cytometry analysis. The HCT116, HCT15, and DLD1 CRC cells were treated with 0,10 , 20 and $40 \mu \mathrm{M}$ of rhein for $48 \mathrm{~h}$ and then the apoptosis was analyzed. Results demonstrated that rhein induced apoptosis in HCT116, HCT15, and DLD1 cells in a dose-dependent manner (Fig. 3d, e). In addition, the apoptotic marker proteins p53, p-p53, cleaved caspase 3 and Bax were strongly upregulated in CRC cells treated with rhein (Fig. 3f).

\section{mTOR is highly expressed in CRC tissues and cells}

Studies have demonstrated that a high expression of mTOR, as a biomarker in various cancers, was associated with poor prognosis [22-24]. An immunohistochemical study performed in 154 patients, showed that p-mTOR (Ser2448) and p-p70S6K (Thr389) were overexpressed in CRC tumor tissues compared to that in normal colon tissues [25]. In the present study, we evaluated the role of mTOR in CRC by examining the expression of mTOR in a CRC tumor microarray that included 70 pairs of cancer tissues and adjacent cancer tissues (Fig. 4a). We observed that total mTOR was significantly overexpressed in cancer compared to that in adjacent cancer tissues (Fig. 4a). We also evaluated the mTOR expression in CRC cell lines and found that mTOR was highly expressed in CRC cell lines, especially in HCT116 and HCT15 cells, compared to that in the normal colon epithelial cell line CCD-18Co (Fig. 4b). These results demonstrate that $\mathrm{mTOR}$ is a potential therapeutic molecular target for CRC treatment.

\section{Rhein directly targets mTOR and suppresses mTOR signaling pathway in CRC cells}

It has been reported rhein induces apoptosis through regulation of the PI3K/AKT/mTOR signaling pathway in human lung cancer A549 cells [26] and inhibits autophagy by regulating AMPK/mTOR signaling in rat renal tubular cells [27]. To determine whether rhein can directly targeting mTOR protein, we carried out in vitro pull-down assays using rhein-conjugated Sepharose 4B beads (or Sepharose 4B beads only as a negative control) and HCT116 or HCT15 cell lysate (Fig. 4c). Our results demonstrated 
that rhein directly binds to mTOR protein (Fig. 4c). We then investigated the effect of rhein on mTOR/p70S6K pathways in CRC cells. Results showed that treatment with rhein inhibited p-mTOR and pp70S6K in both HCT15 and HCT116 cells (Fig. 4d). Studies have demonstrated that HSF1 activation in multiple cancers is strongly associated with tumor metastasis and death [28] and that mTOR is essential for HSF1 activation and HSP90 synthesis [29]. Therefore, we detected the HSF1 and HSP90 expression after treatment with rhein in HCT15 and HCT116 cells. As expected, the protein levels of HSF1 and HSP90 were also downregulated by rhein treatment in CRC cells (Fig. 4d). In addition, we conducted quantitative real-time PCR to evaluate the mRNA levels of HSF1, HSP90, and LDHA. The mRNA levels of HSP90 and LDHA were decreased in the rhein-treated HCT116 cells (Additional file 1: Fig. S1). Results of immunofluorescence analysis showed that mTOR expression was suppressed after rhein treatment compared to that in control (Fig. 4e). These data indicate that rhein directly targets mTOR and suppresses mTOR/p70S6K signaling pathway in CRC cells.

\section{Overexpression of mTOR promotes the proliferation, anchorage-independent colony formation, migration and invasion of CRC cells}

For assessing the functional role of $\mathrm{MTOR}$ in CRC progression, we established three stable mTORoverexpressing CRC cell lines. Results of western blotting confirmed a significant increase of mTOR expression in HCT116, HCT15, and DLD1 cells compared with control cells (Fig. 5a). Results of the CCK-8 assays and anchorage-independent colony formation assay results demonstrated that overexpressing mTOR promoted the proliferation and anchorage-independent colony formation abilities of CRC cells (Fig. 5b-d). Moreover, overexpression of mTOR remarkably enhanced the migration and invasion abilities of CRC cells as measured by transwell assays (Fig. 5e-h).

\section{Knockdown of mTOR suppressed the proliferation, anchorage-independent colony formation, migration, and invasion of CRC cells}

To elucidate the effect of knockdown of mTOR in CRC cells, endogenous mTOR expression in HCT116 and HCT15 cells was silenced using a lentiviral vector carrying shRNA specifically targeting mTOR (Fig. 6a). As shown in Fig. 6b-d, cell proliferation and anchorage-independent colony formation abilities were significantly inhibited after the downregulation of mTOR expression. However, treatment with rhein failed to further reduces the colony numbers in mTOR-knockdown cells (Additional file 2: Fig. S2), indicating that $\mathrm{mTOR}$ is the primary target of rhein in CRC cells proliferation. Furthermore, the migration and invasion abilities were suppressed in the mTOR-knockdown cells compared to that in control cells (Fig. $6 \mathrm{e}-\mathrm{h})$.

\section{Rhein suppresses HCT116 CRC tumor growth in a xenograft mouse model}

To confirm the antitumor activity of rhein in vivo, we established HCT116 xenografts model by injecting human HCT116 cells subcutaneously into the flanks of nude mice to initiate tumor formation. Tumorbearing mice were divided into three groups and intraperitoneally injected with 2 dosages of rhein (10 and $50 \mathrm{mg} / \mathrm{kg}$ ) and vehicle 3 times per week for 34 days. We observed that treatment with rhein (10 or 
$50 \mathrm{mg} / \mathrm{kg}$ body weight) significantly inhibited tumor growth compared to vehicle-treated mice (Fig. 7a, c). Meanwhile, treatment with rhein had no effect on body weight as no significant differences between the vehicle- and rhein-treated mice (Fig. 9b). These data demonstrated that rhein could effectively inhibit the tumor growth in vivo without exhibiting an obvious toxicity. In addition, we detected the expression of $\mathrm{p}$ mTOR, p-p70S6K, p70S6K, Cyclin D1 proteins in the tumor tissues. The expression of p-mTOR, p-p70S6K, p70S6K, Cyclin D1 were significantly inhibited after treatment with rhein in xenograft tumors at doses of $10 \mathrm{mg} / \mathrm{kg}$ and $50 \mathrm{mg} / \mathrm{kg}$ body weight compared to those in vehicle-treated tumors (Fig. 7d). H\&E staining results showed no histological abnormalities in the liver and lung in the treatment groups (Fig. 7e). In addition, IHC analysis was conducted to evaluate the protein levels of Ki67, HSF1, Cyclin D1, or Cyclin A1 in HCT116 xenograft tumors, and the results showed that rhein decreased the expression of these protein markers (Fig. 7f, g). Overall, these results demonstrated that rhein effectively inhibited CRC tumor growth through mTOR/p70S6K pathway in vivo and has the potential to be used as a chemotherapeutic agent for CRC.

\section{Discussion}

Rhein is a natural anthraquinone found in several medicinal plants [10], and it has been reported to possess a wide range of biological activities. Recent studies have demonstrated that rhein exhibited potent efficacy in inhibiting tumor growth $[11,12,17,30]$. However, the mechanisms underlying its anticancer effects of rhein remain poorly elucidated. In the present study, we found that mTOR was highly expressed in the CRC patients tumor tissues (Fig. 4a) and CRC cells (Fig. 4b). We further demonstrated that rhein exerted an anticancer activity by suppressing mTOR/p70S6K signal pathway in vitro and in vivo.

Dysregulation of the Akt/mTOR pathway has been found in various cancer types, including CRC. The Akt/mTOR signaling is essential for the proliferation, metabolism and angiogenesis [31]. Studies have reported that inhibition of mTOR effectively suppressed tumor growth in several cancers, including bladder [32], breast [33], pancreatic [34, 35], and colon [6, 9] cancers. mTORC1 and mTORC2 are the two different complexes of mTOR. mTORC1 phosphorylates P70S6K and eukaryotic initiation factor 4Ebinding protein 1 (4E-BP1), which leads to increased cell proliferation [36, 37]. mTORC2 and its associated protein rictor phosphorylates Akt at Ser 473, thereby leding to activation of the Akt pathway [38]. In our study, we found that rhein treatment effectively downregulated the p-mTOR (Ser2448) and p-p70S6K (Thr389) in CRC cells (Fig. 4d) and xenograft tumor tissues (Fig. 7d), thereby suggesting that rhein inhibits the functions of mTOR and p70S6K.

HSF1 is a master regulator of the heat shock response, which can promote malignant transformation, cancer cell proliferation, and survival [28]. Recent studies showed that HSF1 can act as an oncogene and be strongly related to advanced tumor progression and poor prognosis in gastric cancer [39], and breast cancer $[40,41]$. A previous study demonstrated that mTOR is essential for the HSF1 activation and heat shock protein synthesis [29]. In the present study, we found HSF1 is highly expression in CRC cells, and 
rhein treatment downregulated the expression of HSF1 and its downstream HSP90 protein level through mTOR inhibition.

Cell cycle progression is monitored strictly by cyclin-dependent kinases (CDKs) and their partner cyclins [42]. The Cyclin A/CDK2 complex is required for progression through the $S$ phase [43]. S phase cell cycle arrest was observed in cells with hypoxia [44], DNA damage [45], and chemotherapy [46, 47]. Moreover, the mTOR/p70S6K pathway has been reported to be involved in DNA damage [48]. Previous research has demonstrated that rhein suppresses HepaRG cell growth through S phase cell cycle arrest [12], which is consistent with the results of the present study. Our results showed that rhein induced $\mathrm{S}$ phase cell cycle arrest in CRC cells through downregulation of Cyclin A1, Cyclin E1, and CDK2.

Cancer metastasis is known to be a major cause of treatment failure. The epithelial-mesenchymal transition (EMT) is a key mechanism involved in cancer metastasis [49]. During EMT process, epithelial cells transform into migrating and infiltrating cells, and cancer cells appear to lose epithelial markers such as E-cadherin and acquire mesenchymal markers such as N-cadherin [50]. In the present study, we found that rhein decreased the levels of $\mathrm{N}$-cadherin and vimentin and increased the levels of E-cadherin in CRC cells, showing that rhein can suppress the EMT process of CRC cells (Fig. 2). In addition, our results indicated that mTOR plays an important role in the EMT process. Overexpression of mTOR could promote CRC cells migration and invasion (Fig. 5), whereas knockdown of mTOR could inhibit CRC cells migration and invasion (Fig. 6). To our knowledge, our study is the first to report that mTOR promotes the migration and invasion of CRC cells.

Cell line-derived tumor xenograft models are the most commonly used for assessing cancer therapeutic efficacy. To further explore the anticancer effect of rhein in vivo, we established the HCT116 xenografts model. Our results showed that intraperitoneal injection of rhein dramatically suppressed CRC tumor growth in xenograft models (Fig. 7a) without causing toxicity based on our observations of no significant loss of body weight loss, and histological lesions of liver or lung tissues compared to those in vehicle group mice (Fig. 7b, e). p-mTOR and p-p70S6K were found to be downregulated in tumor tissues lysis, which further confirmed that rhein suppressed CRC cell growth through mTOR/p70S6K pathway.

\section{Conclusions}

In summary, our study reveals that mTOR/p70S6K signaling plays a vital role in the progression of CRC. We demonstrated that rhein inhibited CRC cells growth in vitro and in vivo by direct targeting $\mathrm{mTOR}$ and suppressing mTOR/p70S6K signaling pathway. Our study indicates that rhein might be a potential antitumor agent for CRC prevention and treatment.

\section{Abbreviations}

CRC: Colorectal cancer

PI3K: Phosphoinositide 3-kinase 
Akt: Protein kinase B

mTOR: Mammalian target of rapamycin

Raptor: Regulatory-associated protein of mTOR

p70S6 kinase: Ribosomal protein S6 kinase beta-1

4E-BP1: Eukaryotic translation initiation factor 4E-binding protein 1

Bax: Bcl-2-associated X protein

BSA: Bovine serum albumin

CDK2: Cyclin-dependent kinase 2

HSF1: Heat shock factor 1

HSP90: Heat shock protein 90

LDHA: Lactate dehydrogenase A

DAPI: 4, 6-diamidino-2-phenylindole dihydro-chloride

EMT: Epithelial-mesenchymal transition

IC50: Half maximal inhibitory concentrations

Pl: Propidium iodide

DMSO: Dimethyl sulfoxide

\section{Declarations}

\section{Acknowledgements}

No applicable.

\section{Funding}

No funding was received.

\section{Authors' contributions}

HBZ and HH performed the in vitro experiments, HBZ, SP, SJP, SYK and WBK assisted in animal experiments; JKY, SYJ, EYK assisted with data analysis; SKC, SHK, KDL and ZGD supervised the in vitro 
experimental; HBZ analysed the data and wrote the manuscript. MOK and ZYR supervised the experiments and revised the manuscript. All authors read and approved the final manuscript.

\section{Availability of data and materials}

The datasets used and analyzed in the current study are available from the corresponding author on reasonable request.

\section{Ethics approval and consent to participate}

All animal experiments were performed in accordance with the ethical standards of the Animal Care and Use Committee of Kyungpook National University.

\section{Consent for publication}

The authors declare that they agree to submit the article for publication.

\section{Competing interests}

The authors declare that they have no competing interests.

\section{References}

1. Siegel RL, Miller KD, Goding Sauer A, Fedewa SA, Butterly LF, Anderson JC, Cercek A, Smith RA, Jemal A. Colorectal cancer statistics, 2020. CA: a cancer journal for clinicians 2020.

2. Fearon ER. Molecular genetics of colorectal cancer. Annu Rev Pathol. 2011;6:479-507.

3. Vogelstein B, Kinzler KW. Cancer genes and the pathways they control. Nature medicine. 2004;10(8):789.

4. Laplante M, Sabatini DM. mTOR Signaling. Cold Spring Harbor perspectives in biology 2012, 4(2).

5. Laplante M, Sabatini DM. mTOR signaling in growth control and disease. Cell. 2012;149(2):274-93.

6. Wang H, Liu Y, Ding J, Huang Y, Liu J, Liu N, Ao Y, Hong Y, Wang L, Zhang L, et al: Targeting mTOR suppressed colon cancer growth through 4EBP1/elF4E/PUMA pathway. Cancer gene therapy 2019.

7. Ponnurangam S, Standing D, Rangarajan P, Subramaniam D. Tandutinib inhibits the Akt/mTOR signaling pathway to inhibit colon cancer growth. Mol Cancer Ther. 2013;12(5):598-609.

8. You S, Li W, Guan Y. Tunicamycin inhibits colon carcinoma growth and aggressiveness via modulation of the ERK-JNK-mediated AKT/mTOR signaling pathway. Mol Med Rep. 2018;17(3):4203-12.

9. Pandurangan AK, Ismail S, Esa NM, Munusamy MA. Inositol-6 phosphate inhibits the mTOR pathway and induces autophagy-mediated death in HT-29 colon cancer cells. Archives of medical science: AMS. 2018;14(6):1281-8. 
10. Zhou YX, Xia W, Yue W, Peng C, Rahman K, Zhang H. Rhein: A Review of Pharmacological Activities. Evidence-based complementary alternative medicine: eCAM. 2015;2015:578107.

11. Yang L, Li J, Xu L, Lin S, Xiang Y, Dai X, Liang G, Huang X, Zhu J, Zhao C. Rhein shows potent efficacy against non-small-cell lung cancer through inhibiting the STAT3 pathway. Cancer management research. 2019;11:1167-76.

12. You L, Dong X, Yin X, Yang C, Leng X, Wang W, Ni J. Rhein Induces Cell Death in HepaRG Cells through Cell Cycle Arrest and Apoptotic Pathway. International journal of molecular sciences 2018, $19(4)$.

13. Chang CY, Chan HL, Lin HY, Way TD, Kao MC, Song MZ, Lin YJ, Lin CW. Rhein induces apoptosis in human breast cancer cells. Evidence-based complementary alternative medicine: eCAM. 2012;2012:952504.

14. Lin YJ, Zhen YS. Rhein lysinate suppresses the growth of breast cancer cells and potentiates the inhibitory effect of Taxol in athymic mice. Anti-cancer drugs. 2009;20(1):65-72.

15. Ren B, Guo W, Tang Y, Zhang J, Xiao N, Zhang L, Li W. Rhein Inhibits the Migration of Ovarian Cancer Cells through Down-Regulation of Matrix Metalloproteinases. Biol Pharm Bull. 2019;42(4):568-72.

16. Han NN, Li X, Tao L, Zhou Q. Doxorubicin and rhein loaded nanomicelles attenuates multidrug resistance in human ovarian cancer. Biochem Biophys Res Commun. 2018;498(1):178-85.

17. Yuan X, Tian W, Hua Y, Hu L, Yang J, Xie J, Hu J, Wang F. Rhein enhances the cytotoxicity of effector lymphocytes in colon cancer under hypoxic conditions. Experimental therapeutic medicine. 2018;16(6):5350-8.

18. Vilella-Bach M, Nuzzi P, Fang Y, Chen J. The FKBP12-rapamycin-binding domain is required for FKBP12-rapamycin-associated protein kinase activity and G1 progression. J Biol Chem. $1999 ; 274(7): 4266-72$.

19. Steeg PS. Targeting metastasis. Nature reviews Cancer. 2016;16(4):201-18.

20. Averous J, Fonseca BD, Proud CG. Regulation of cyclin D1 expression by mTORC1 signaling requires eukaryotic initiation factor 4E-binding protein 1. Oncogene. 2008;27(8):1106-13.

21. Zhang X, Cheng D, Liu Y, Wu Y, He Z. Gephyrin suppresses lung squamous cell carcinoma development by reducing mTOR pathway activation. Cancer management research. 2019;11:533341.

22. Li SH, Chien CY, Huang WT, Luo SD, Su YY, Tien WY, Lan YC, Chen CH. Prognostic significance and function of mammalian target of rapamycin in tongue squamous cell carcinoma. Scientific reports. 2017;7(1):8178.

23. Ghosh AP, Marshall CB, Coric T, Shim EH, Kirkman R, Ballestas ME, Ikura M, Bjornsti MA, Sudarshan S. Point mutations of the mTOR-RHEB pathway in renal cell carcinoma. Oncotarget. 2015;6(20):17895-910.

24. Wang W, Wen Q, Xu L, Xie G, Li J, Luo J, Chu S, Shi L, Huang D, Li J, et al. Activation of Akt/mTOR pathway is associated with poor prognosis of nasopharyngeal carcinoma. PloS one. 2014;9(8):e106098. 
25. Cancer Genome Atlas N. Comprehensive molecular characterization of human colon and rectal cancer. Nature. 2012;487(7407):330-7.

26. Bu T, Wang C, Jin H, Meng Q, Huo X, Sun H, Sun P, Wu J, Ma X, Liu Z, et al. Organic anion transporters and PI3K-AKT-mTOR pathway mediate the synergistic anticancer effect of pemetrexed and rhein. Journal of cellular physiology. 2020;235(4):3309-19.

27. Tu Y, Gu L, Chen D, Wu W, Liu H, Hu H, Wan Y, Sun W. Rhein Inhibits Autophagy in Rat Renal Tubular Cells by Regulation of AMPK/mTOR Signaling. Scientific reports. 2017;7:43790.

28. Mendillo ML, Santagata S, Koeva M, Bell GW, Hu R, Tamimi RM, Fraenkel E, Ince TA, Whitesell L, Lindquist S. HSF1 drives a transcriptional program distinct from heat shock to support highly malignant human cancers. Cell. 2012;150(3):549-62.

29. Chou SD, Prince T, Gong J, Calderwood SK. mTOR is essential for the proteotoxic stress response, HSF1 activation and heat shock protein synthesis. PloS one. 2012;7(6):e39679.

30. Zhuang Y, Bai Y, Hu Y, Guo Y, Xu L, Hu W, Yang L, Zhao C, Li X, Zhao H. Rhein sensitizes human colorectal cancer cells to EGFR inhibitors by inhibiting STAT3 pathway. Onco Targets Ther. 2019;12:5281-91.

31. Saxton RA, Sabatini DM. mTOR Signaling in Growth, Metabolism, and Disease. Cell. 2017;169(2):361-71.

32. lida K, Naiki T, Naiki-lto A, Suzuki S, Kato H, Nozaki S, Nagai T, Etani T, Nagayasu Y, Ando R, et al: Luteolin suppresses bladder cancer growth via regulation of mechanistic target of rapamycin (mTOR) pathway. Cancer science 2020.

33. Carraway H, Hidalgo M. New targets for therapy in breast cancer: mammalian target of rapamycin (mTOR) antagonists. Breast cancer research: BCR. 2004;6(5):219-24.

34. Totiger TM, Srinivasan S, Jala VR, Lamichhane P, Dosch AR, Gaidarski AA 3rd, Joshi C, Rangappa S, Castellanos J, Vemula PK, et al. Urolithin A, a Novel Natural Compound to Target PI3K/AKT/mTOR Pathway in Pancreatic Cancer. Mol Cancer Ther. 2019;18(2):301-11.

35. Nair V, Sreevalsan S, Basha R, Abdelrahim M, Abudayyeh A, Rodrigues Hoffman A, Safe S. Mechanism of metformin-dependent inhibition of mammalian target of rapamycin (mTOR) and Ras activity in pancreatic cancer: role of specificity protein (Sp) transcription factors. J Biol Chem. 2014;289(40):27692-701.

36. Mayhew DL, Hornberger TA, Lincoln HC, Bamman MM. Eukaryotic initiation factor 2B epsilon induces cap-dependent translation and skeletal muscle hypertrophy. J Physiol. 2011;589(Pt 12):3023-37.

37. Zhang Q, Wang X, Cao S, Sun Y, He X, Jiang B, Yu Y, Duan J, Qiu F, Kang N. Berberine represses human gastric cancer cell growth in vitro and in vivo by inducing cytostatic autophagy via inhibition of MAPK/mTOR/p70S6K and Akt signaling pathways. Biomedicine pharmacotherapy = Biomedecine pharmacotherapie. 2020;128:110245.

38. Sarbassov DD, Guertin DA, Ali SM, Sabatini DM. Phosphorylation and regulation of Akt/PKB by the rictor-mTOR complex. Science. 2005;307(5712):1098-101. 
39. Dai W, Ye J, Zhang Z, Yang L, Ren H, Wu H, Chen J, Ma J, Zhai E, Cai S, et al. Increased expression of heat shock factor 1 (HSF1) is associated with poor survival in gastric cancer patients. Diagn Pathol. 2018;13(1):80.

40. Santagata S, Hu R, Lin NU, Mendillo ML, Collins LC, Hankinson SE, Schnitt SJ, Whitesell L, Tamimi RM, Lindquist S, et al. High levels of nuclear heat-shock factor 1 (HSF1) are associated with poor prognosis in breast cancer. Proc Natl Acad Sci USA. 2011;108(45):18378-83.

41. Calderwood SK. Elevated levels of HSF1 indicate a poor prognosis in breast cancer. Future Oncol. 2012;8(4):399-401.

42. Bertoli C, Skotheim JM, de Bruin RA. Control of cell cycle transcription during G1 and S phases. Nat Rev Mol Cell Biol. 2013;14(8):518-28.

43. Echalier A, Endicott JA, Noble ME. Recent developments in cyclin-dependent kinase biochemical and structural studies. Biochim Biophys Acta. 2010;1804(3):511-9.

44. Seim J, Graff P, Amellem O, Landsverk KS, Stokke T, Pettersen EO. Hypoxia-induced irreversible Sphase arrest involves down-regulation of cyclin A. Cell proliferation. 2003;36(6):321-32.

45. Garner KM, Eastman A. Variations in Mre11/Rad50/Nbs1 status and DNA damage-induced S-phase arrest in the cell lines of the NCI60 panel. BMC Cancer. 2011;11:206:201-213.

46. Xue JY, Zhou GX, Chen T, Gao S, Choi MY, Wong YS. Desacetyluvaricin induces S phase arrest in SW480 colorectal cancer cells through superoxide overproduction. Journal of cellular biochemistry. 2014;115(3):464-75.

47. Xu Z, Zhang F, Bai C, Yao C, Zhong H, Zou C, Chen X. Sophoridine induces apoptosis and S phase arrest via ROS-dependent JNK and ERK activation in human pancreatic cancer cells. Journal of experimental clinical cancer research: CR. 2017;36(1):124.

48. Xie X, Hu H, Tong X, Li L, Liu X, Chen M, Yuan H, Xie X, Li Q, Zhang Y, et al. The mTOR-S6K pathway links growth signalling to DNA damage response by targeting RNF168. Nat Cell Biol. 2018;20(3):320-31.

49. Dongre A, Weinberg RA. New insights into the mechanisms of epithelial-mesenchymal transition and implications for cancer. Nat Rev Mol Cell Biol. 2019;20(2):69-84.

50. De Craene B, Berx G. Regulatory networks defining EMT during cancer initiation and progression. Nature reviews Cancer. 2013;13(2):97-110.

\section{Additional Files}

Additional file 1: Fig. S1 Rhein treatment downregulates HSP90 and LDHA mRNA levels in HCT116 cells. The mRNA expression levels of HSF1, HSP90, and LDHA in HCT116 cell lines treated with various concentrations of rhein were determined by qRT-PCR. ${ }^{*} p<0.05$

Additional file 2. Fig. S2 Rhein failed to further reduces the colony numbers in mTOR knockdown cells. a Representative colony photographs taken after mTOR knockdown with or without rhein treatment 
(magnification, 50x). b Anchorage-independent colony number was decreased with or without rhein treatment after mTOR knockdown in HCT116 and HCT15 cells. ${ }^{\star} p<0.05,{ }^{\star} p<0.01,{ }^{\star \star \star} p<0.001$.

\section{Figures}

A

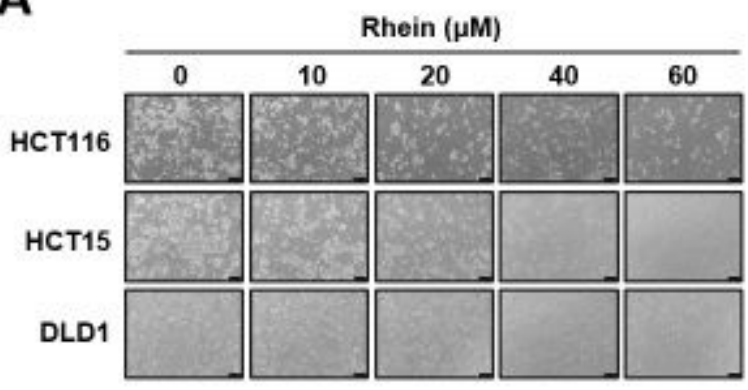

C

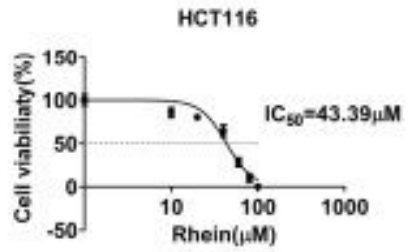

D

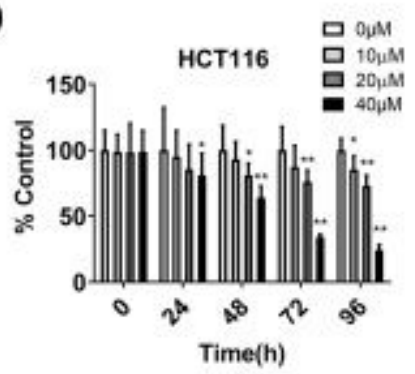

HCT15
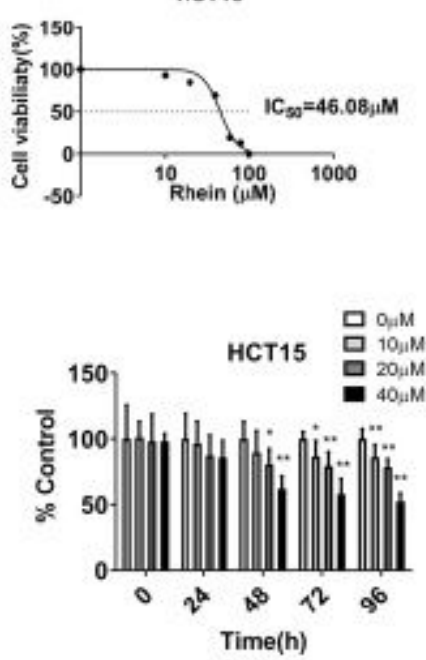

B

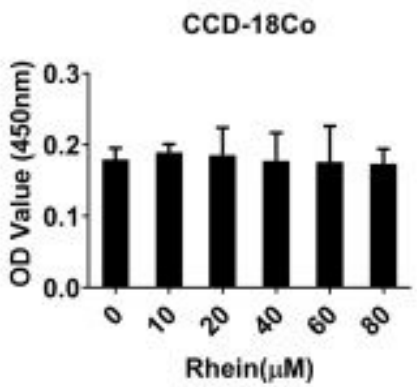

DLD1

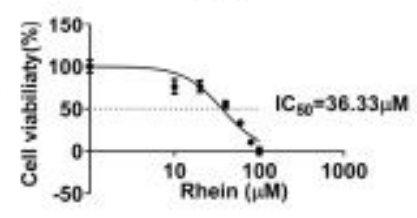

E

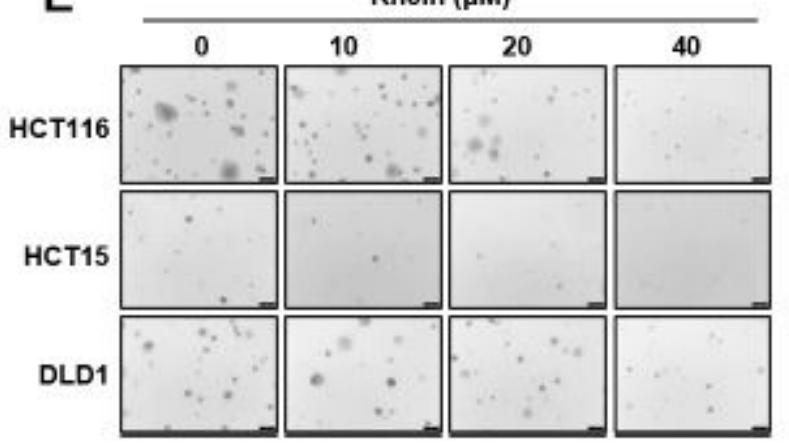

$\mathbf{F}$

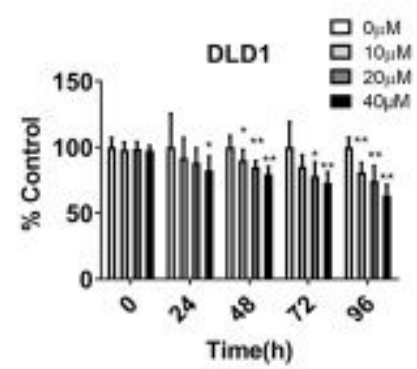

Figure 1

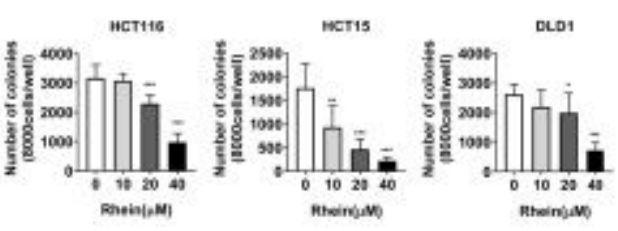

Rhein inhibits the growth of CRC cells. a Morphological changes after treatment with rhein (magnification, 50x). b Cytotoxic effect of rhein on CCD-18Co cells. CCK-8 assay was used after various concentrations of rhein treatment for $72 \mathrm{~h}$. c Cytotoxic effects of rhein on HCT15, HCT116, and DLD1 
cells. CCK-8 assay was used after various concentrations of rhein treatment for $24 \mathrm{~h}$. $\mathrm{d}$ Cell proliferation was determined by CCK-8 assay after rhein treatment for $0,24,48,72$, and $96 \mathrm{~h}$. e-f, Effect of rhein on anchorage-independent growth of CRC cells. ${ }^{*} \mathrm{P}<0.05$, ${ }^{* *} \mathrm{P}<0.01$, ${ }^{* \star *} \mathrm{P}<0.001$.

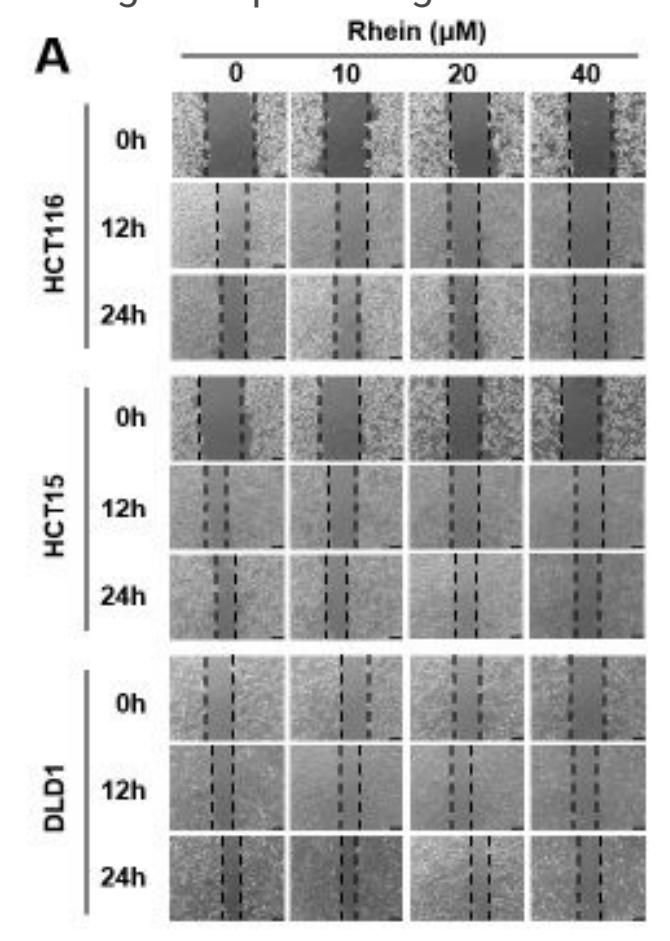

B
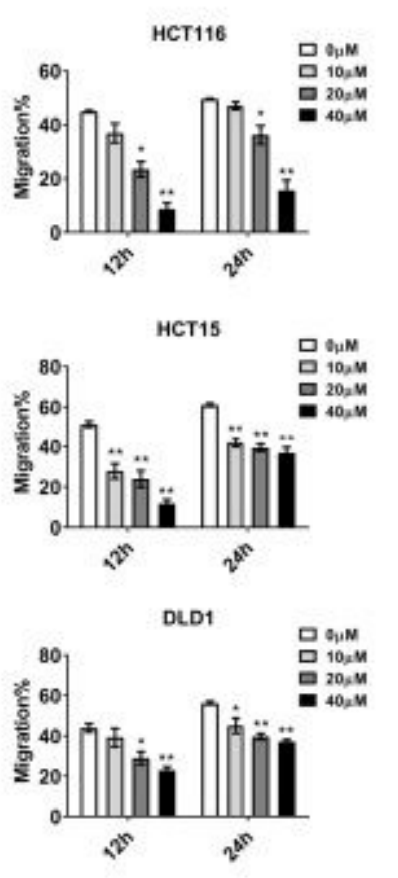

C Migration
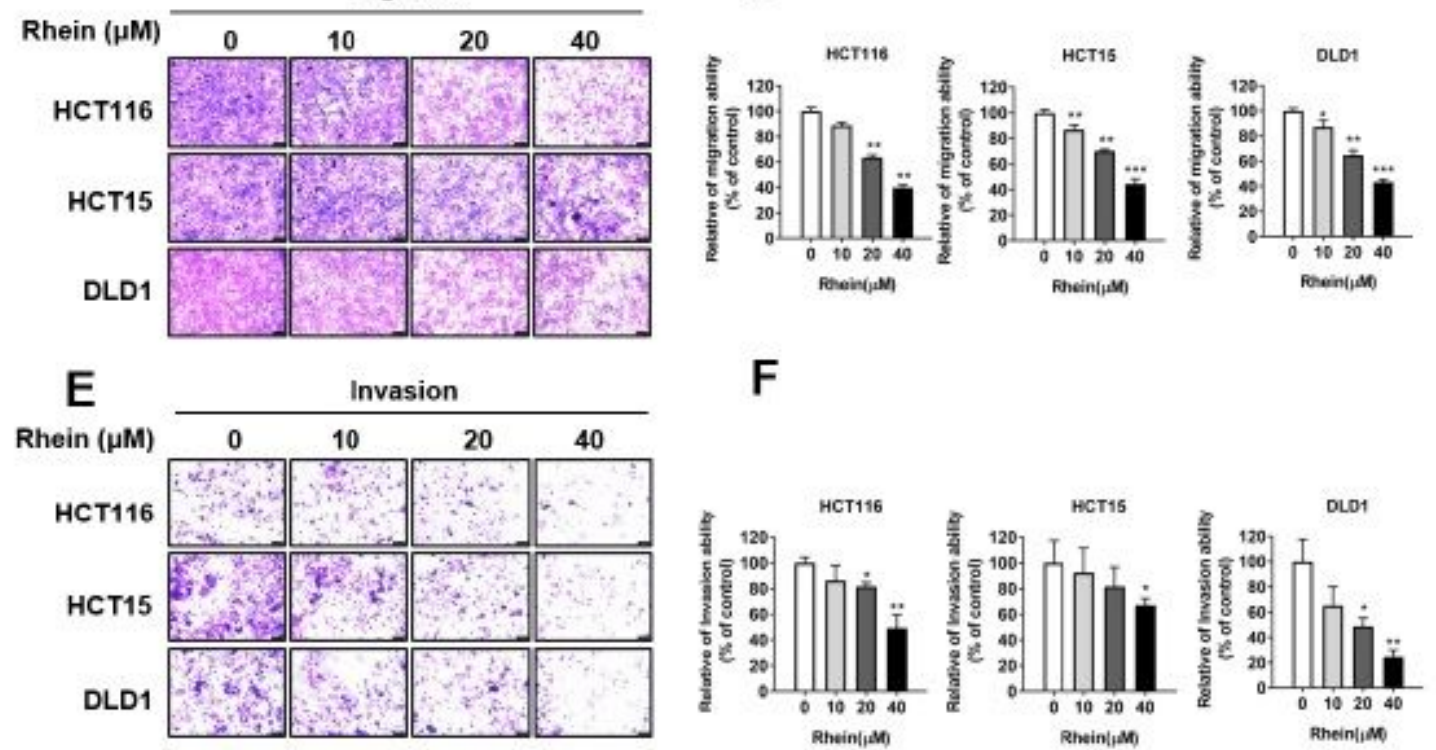

F
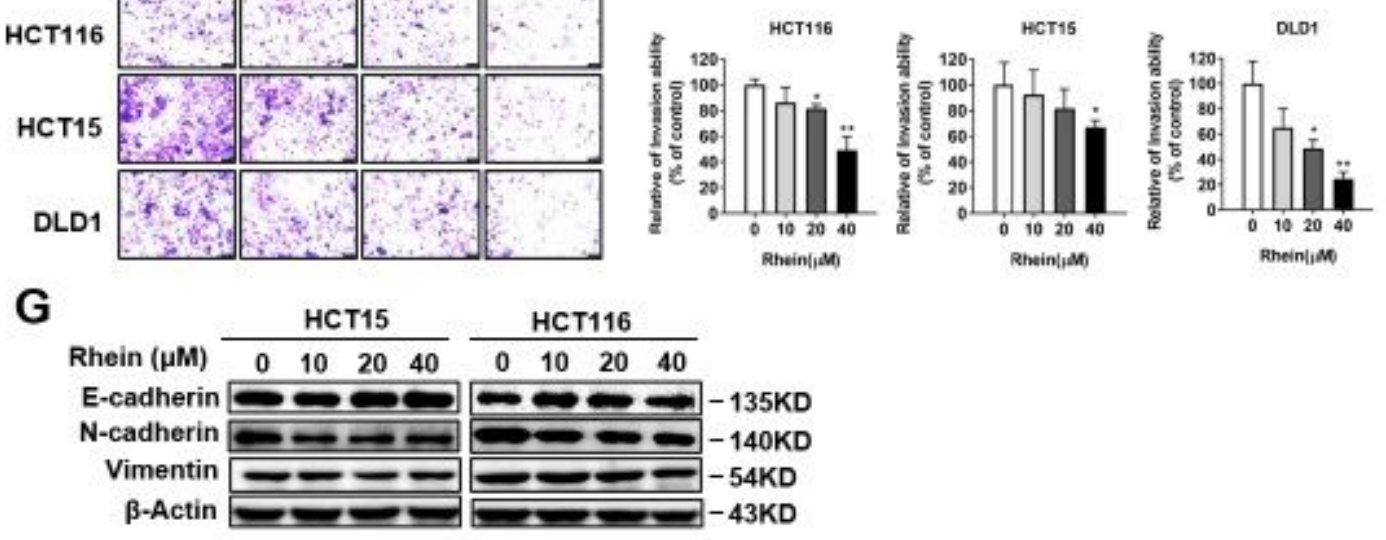

Figure 2

Rhein inhibits the CRC cells migration and invasion. a Wound healing assay was performed to evaluate cell migration in HCT116, HCT15, and DLD1 cells. b Quantitative analysis of the ratio of migration in 
HCT116, HCT15, and DLD1 cells. c Migration assay in HCT116, HCT15, and DLD1 cells. d Quantitative analysis of the ratio of migration in HCT116, HCT15, and DLD1 cells. e Invasion assay in HCT116, HCT15, and DLD1 cells. $f$ Quantitative analysis of the ratio of invasion in HCT116, HCT15, and DLD1 cells. $g$ Western blot analysis the EMT-related proteins in HCT15 and HCT116 cells treated with rhein compared with the control. Magnification, 50x. ${ }^{*} P<0.05$, $* * P<0.01$, $* \star * P<0.001$.
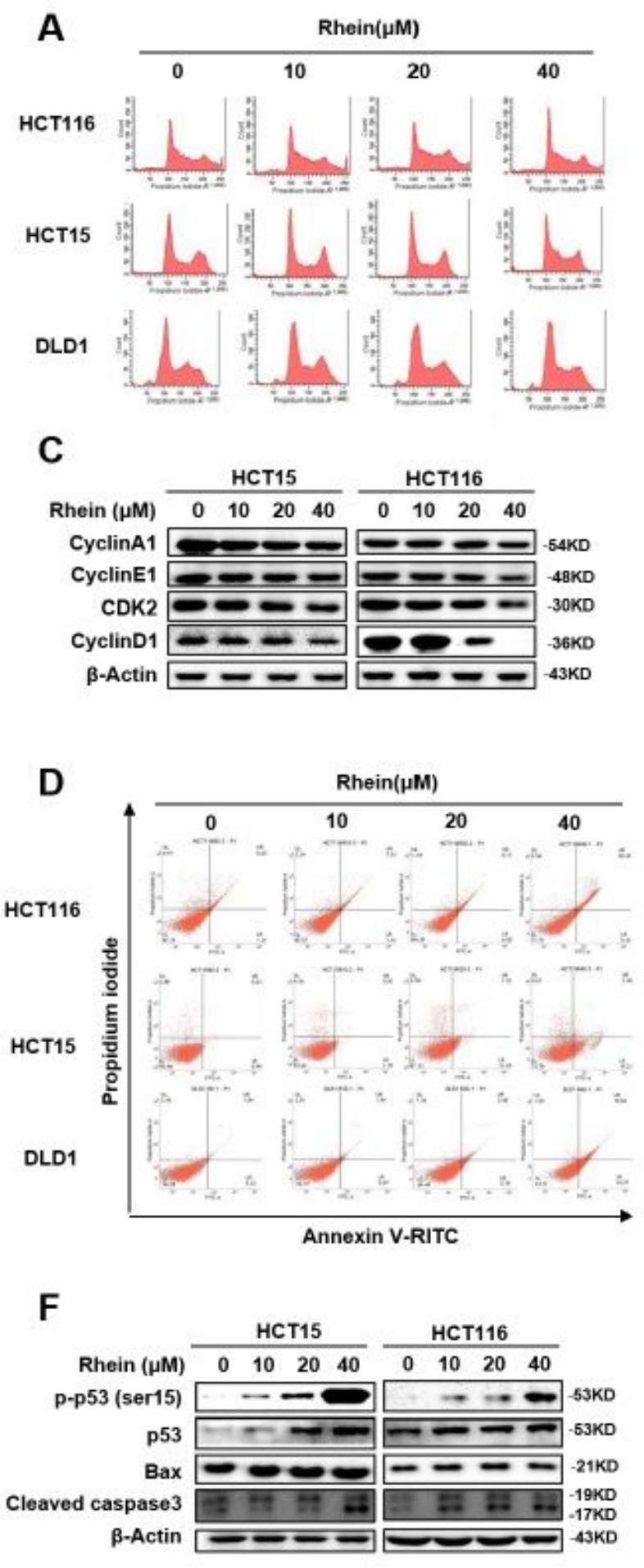
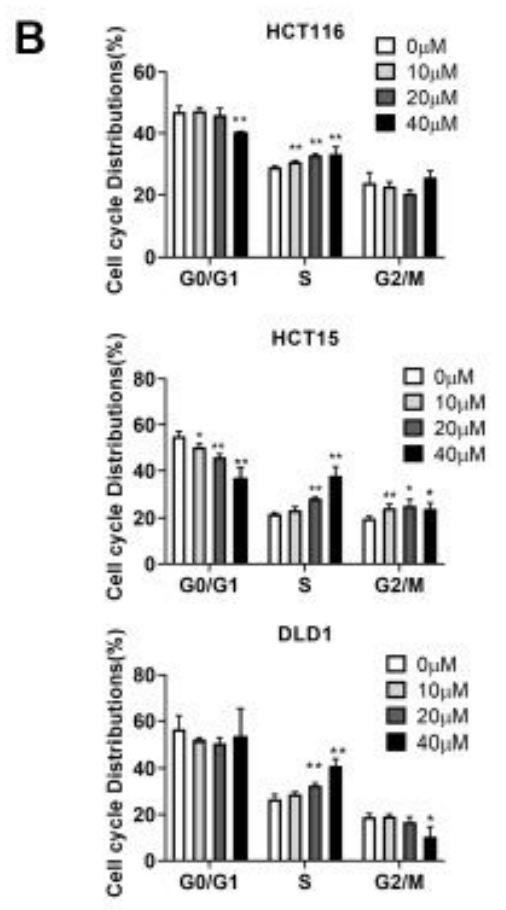

E
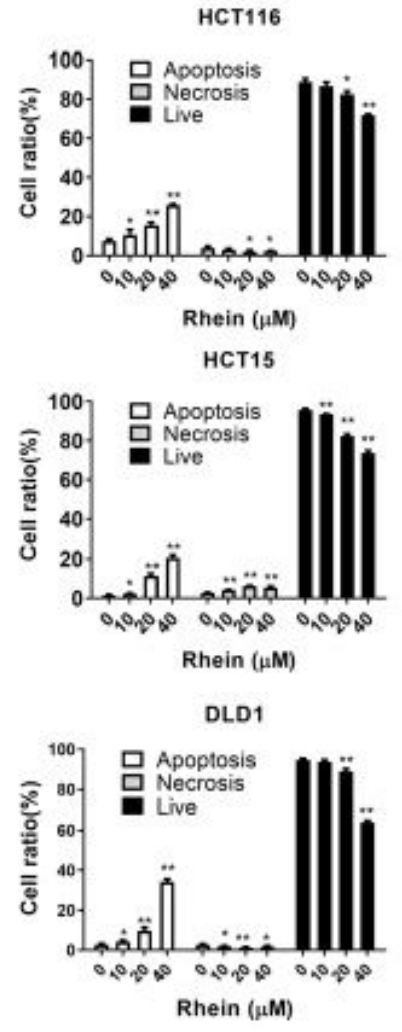

Figure 3 
Rhein induces $S$ phase cell cycle arrest and apoptosis in CRC cells. a-b, Effect of rhein on cell cycle phase. Cells treated with $0,10,20$, or $40 \mu \mathrm{M}$ rhein and then incubated for $48 \mathrm{~h}$ and cell cycle was analyzed by flow cytometry. c Effect of rhein on the expression of $S$ phase-related proteins were detected by western blotting. d-e Cells were treated with $0,10,20$, or $40 \mu \mathrm{M}$ rhein for $48 \mathrm{~h}$, and apoptosis was was detected by flow cytometry. $f$ Effect of rhein on apoptotic marker proteins was detected by western blotting. ${ }^{*} P<0.05$, ${ }^{*} \mathrm{P}<0.01, * * * \mathrm{P}<0.001$.

A

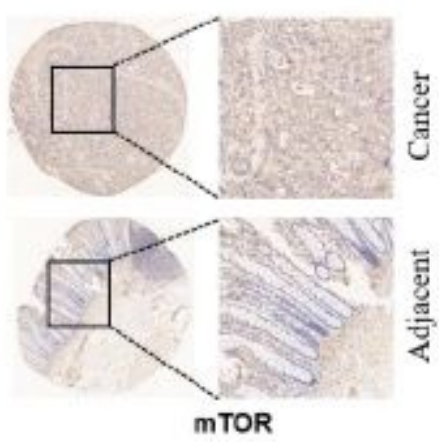

C

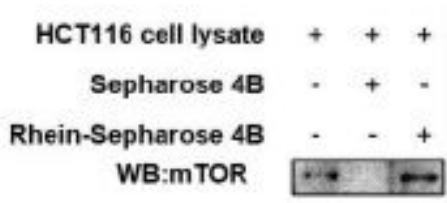

HCT15 cell lysate +++
Sepharose 4B -++
Rhein-Sepharose 4B -++
WB:mTOR $\quad-\quad+$

E

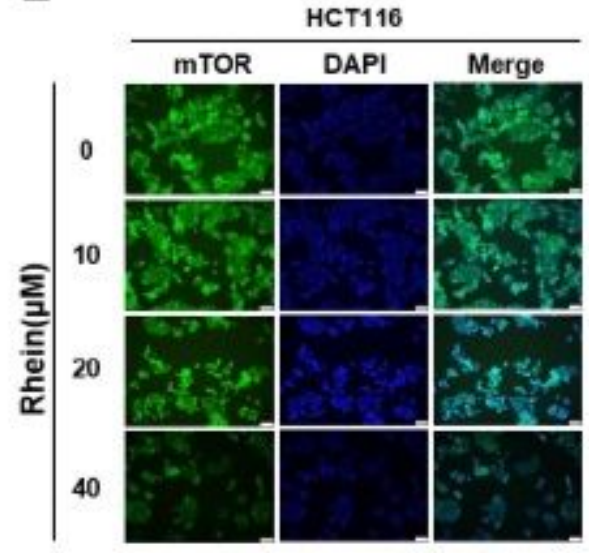

B
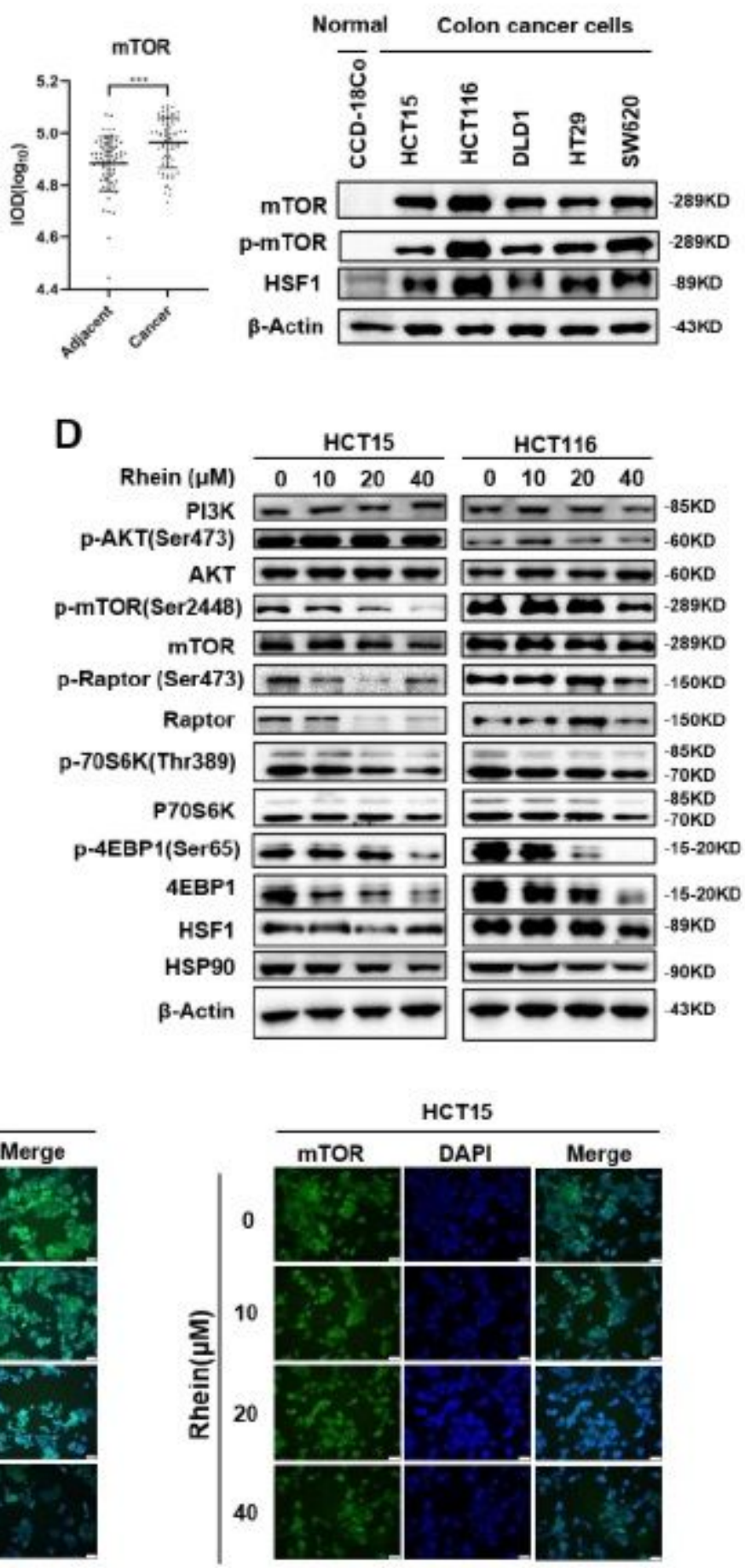

Figure 4 
mTOR is highly expressed in CRC tissues and cells and rhein directly targeting mTOR and suppresses mTOR signaling pathway in CRC cells. a The expression of mTOR was evaluated by IHC analysis on a CRC tumor microarray. b mTOR, p-mTOR, and HSF1 expression levels in CRC cell lines and normal colon normal cell line CCD-18Co were measured by western blotting. c The binding of rhein to mTOR in HCT116 or HCT1 5 cell lysates was determined by western bloting. $d$ The effects of rhein on mTOR signaling pathway in CRC cells were assessed by western blot analysis. e Immunofluorescence results showed mTOR level is decreased after rhein treatment compared to control (magnification, 200x). ${ }^{\star} \mathrm{P}<0.05, * \star \mathrm{P}<$ $0.01,{ }^{*} * \star P<0.001$. 
A
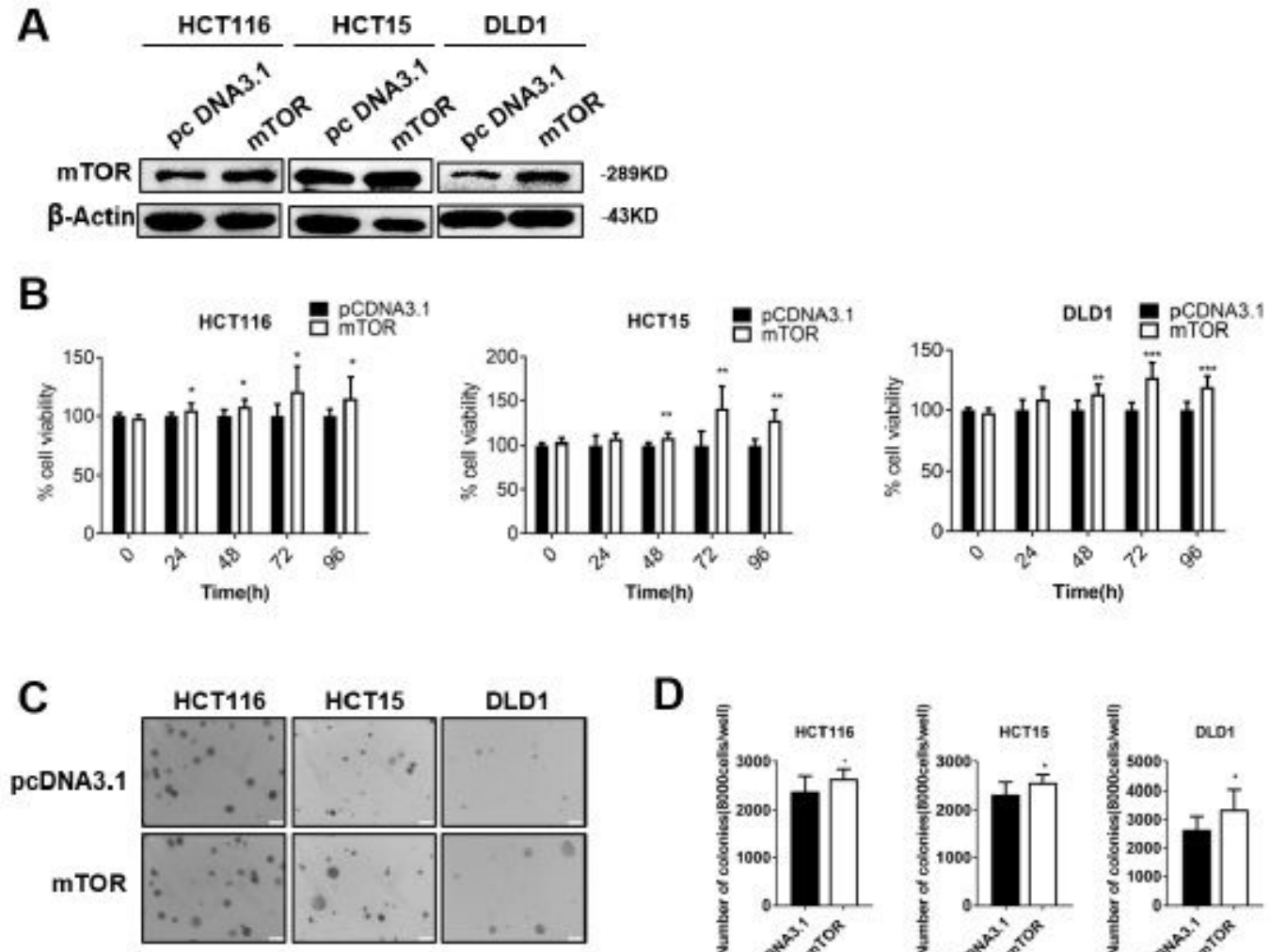

D
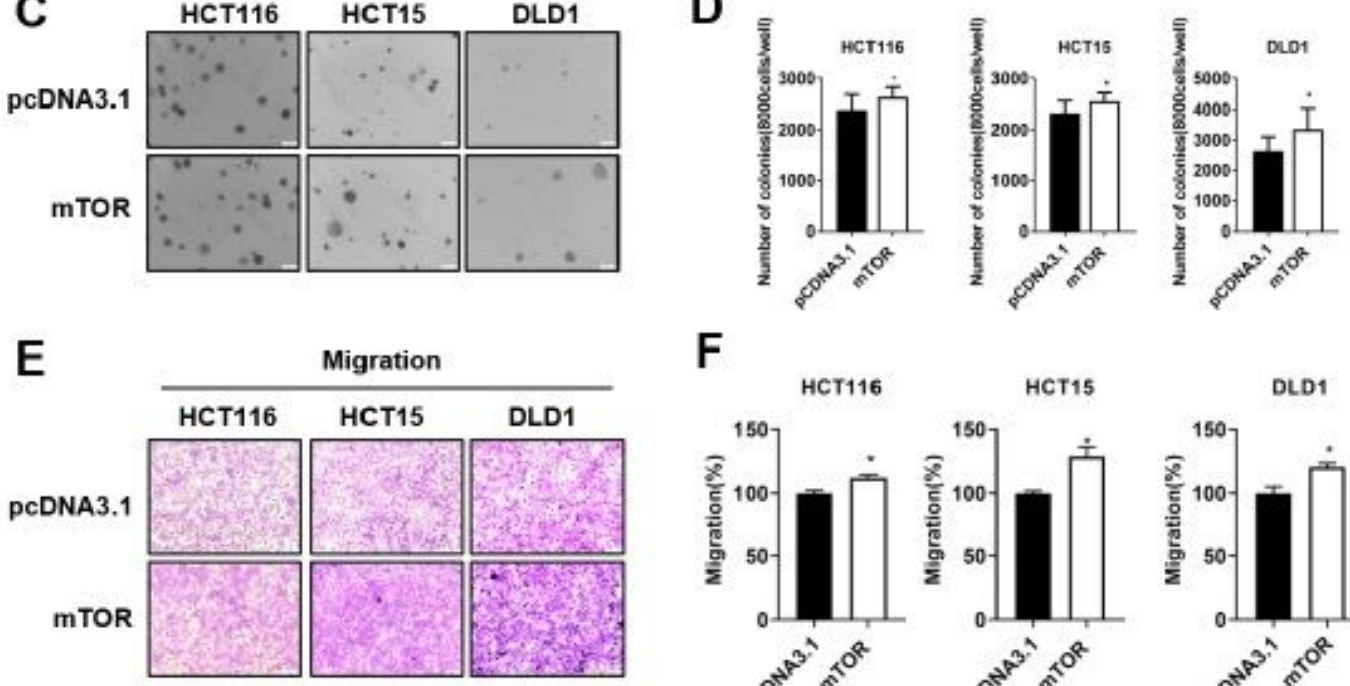

$\mathbf{F}$
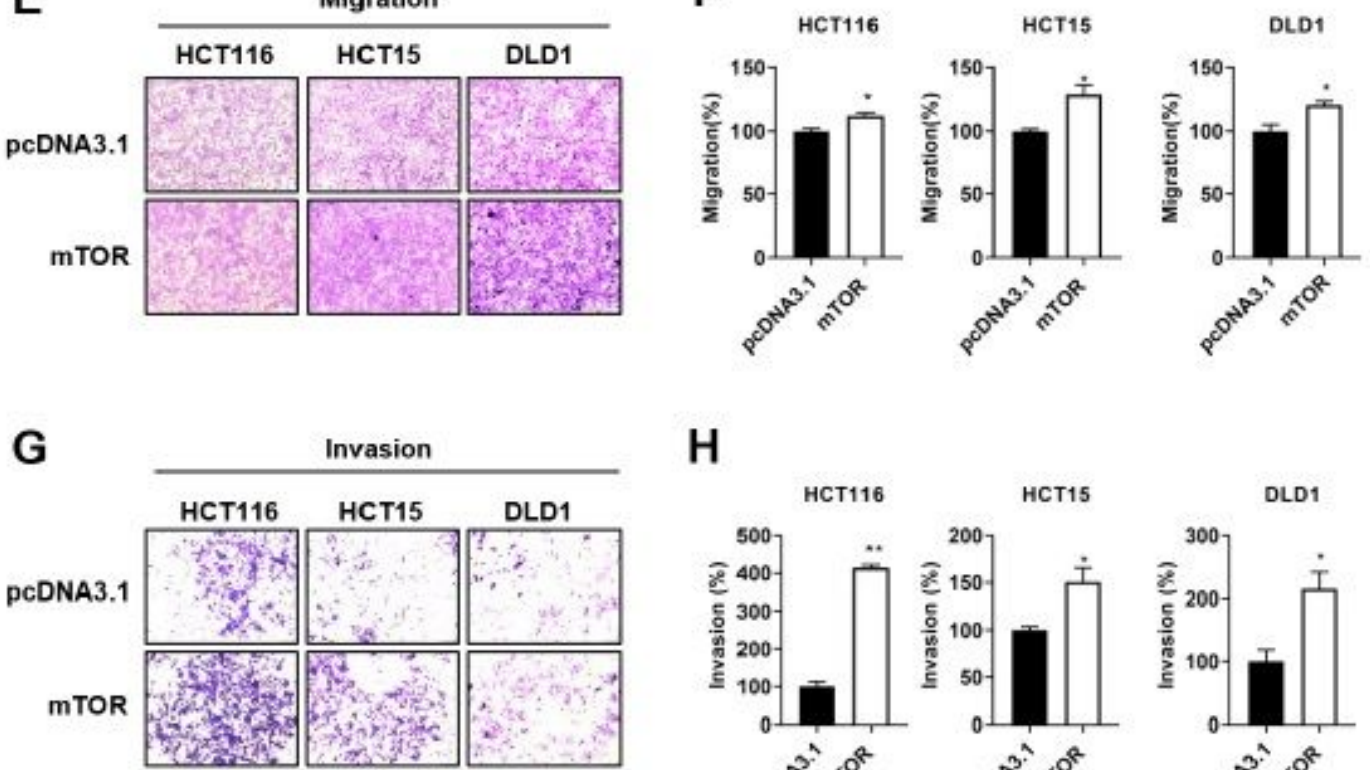

H

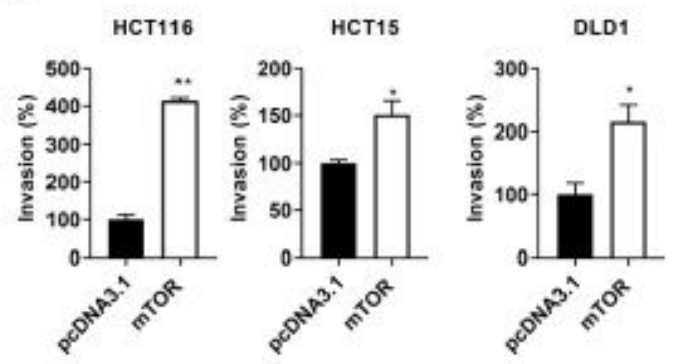

Figure 5

Overexpression of mTOR promotes CRC cells growth. a Overexpression of mTOR in HCT15, HCT116, and DLD1 cell lines was confirmed using western blot assay. b Effects of mTOR overexpression on the proliferation of HCT15, HCT116, and DLD1 cells were assessed by CCK-8 assay. c-d, Anchorageindependent colony formation assays in mTOR-overexpressing cells and control cells of HCT15, HCT116, and DLD1. e, g Representative images of the transwell assay results of cell migration and invasion in 
HCT15, HCT116, and DLD1 cells (mTOR overexpression compared with pcDNA3.1). $f$, h Quantification of the migrated or invaded cells. Magnification, $50 \times .{ }^{*}<0.05$, ${ }^{*} \mathrm{P}<0.01$, ${ }^{* \star *} \mathrm{P}<0.001$.

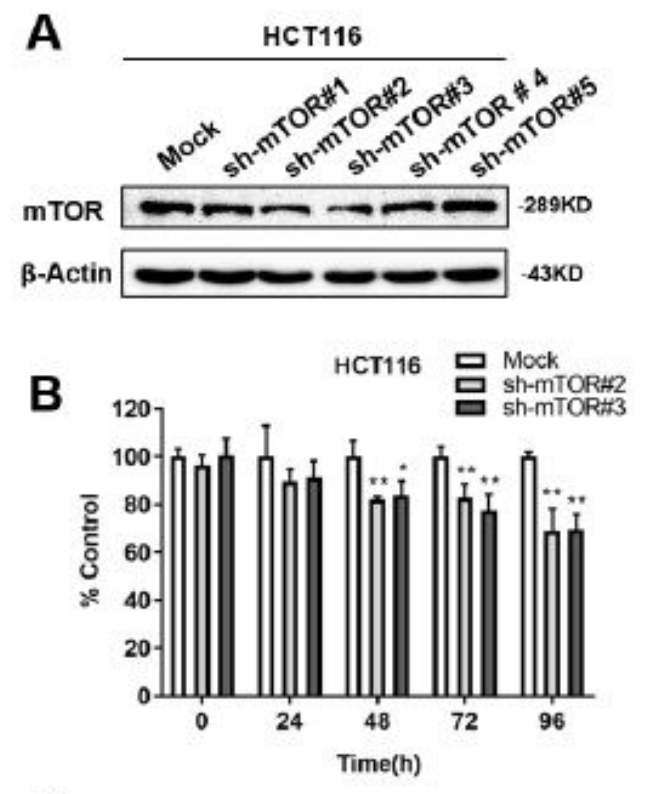

C

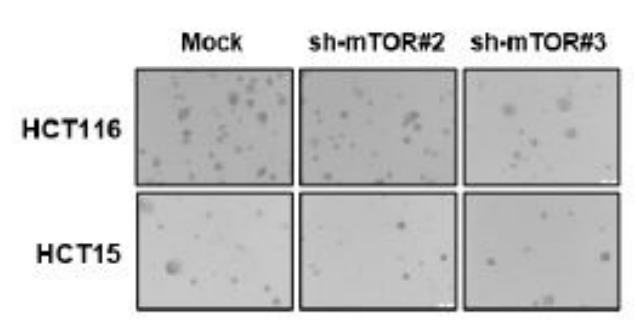

E

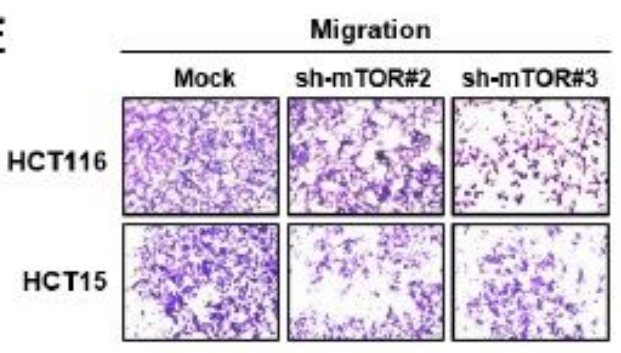

G

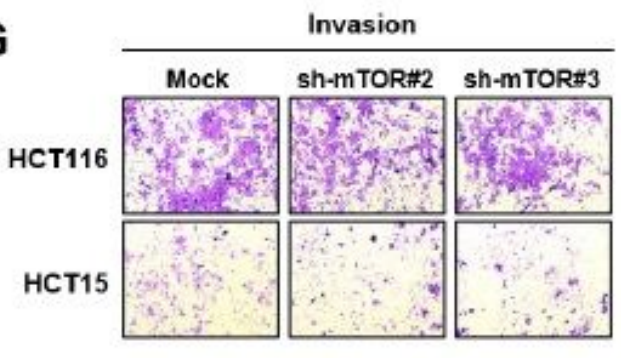

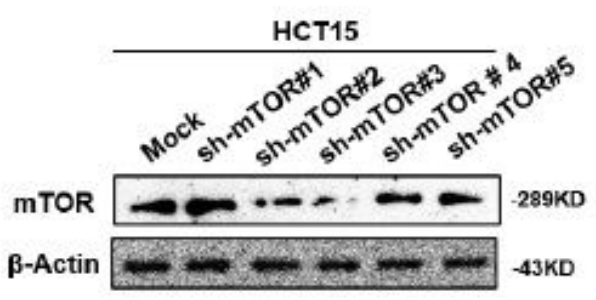
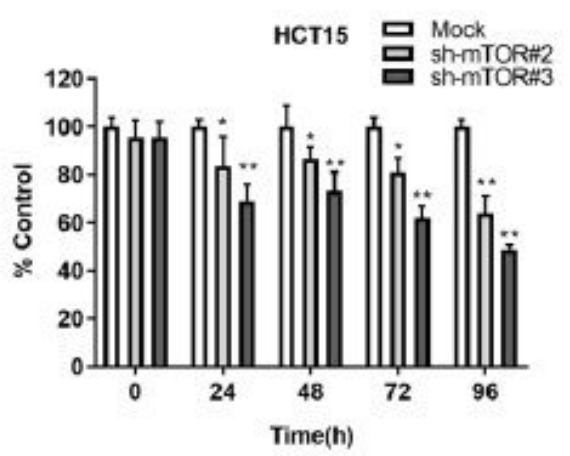

D

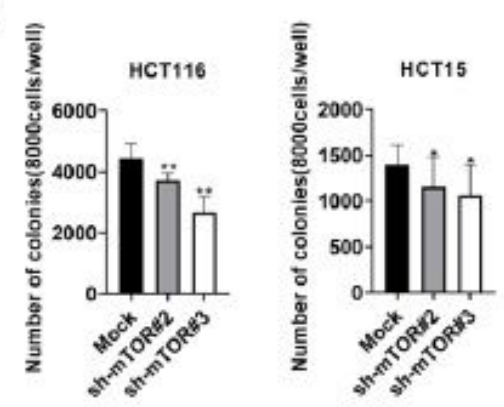

$\mathbf{F}$

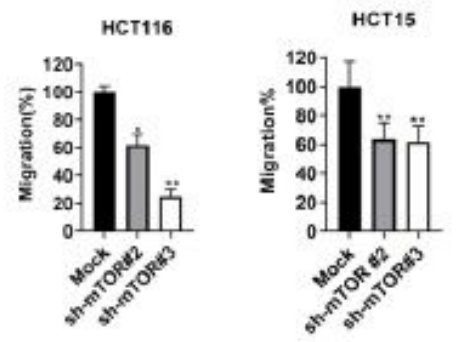

$\mathrm{H}$

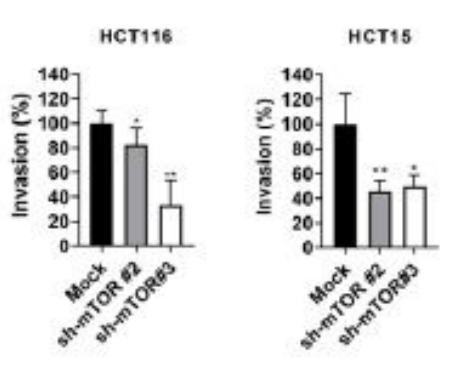

Figure 6

Knockdown of mTOR suppresses CRC cells growth. a mTOR expression was knocked down in HCT116 and HCT15 cell lines. b Knockdown of mTOR inhibited the proliferation in HCT116 and HCT15 cells, as assessed by CCK-8 assay. c-d, Anchorage-independent colony formation assays in mTOR-knockdown 
and control cells of HCT15 and HCT116. e,g Representative images of the transwell assay results of cell migration and invasion in HCT15 and HCT116 cells (sh-mTOR compared with Mock). $\mathrm{f}$, h Quantification of the migrated or invaded cells. Magnification, 50x. ${ }^{*} \mathrm{P}<0.05,{ }^{\star} \mathrm{P}<0.01, * \star * \mathrm{P}<0.001$.

A

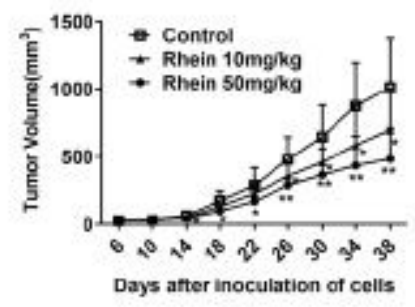

D

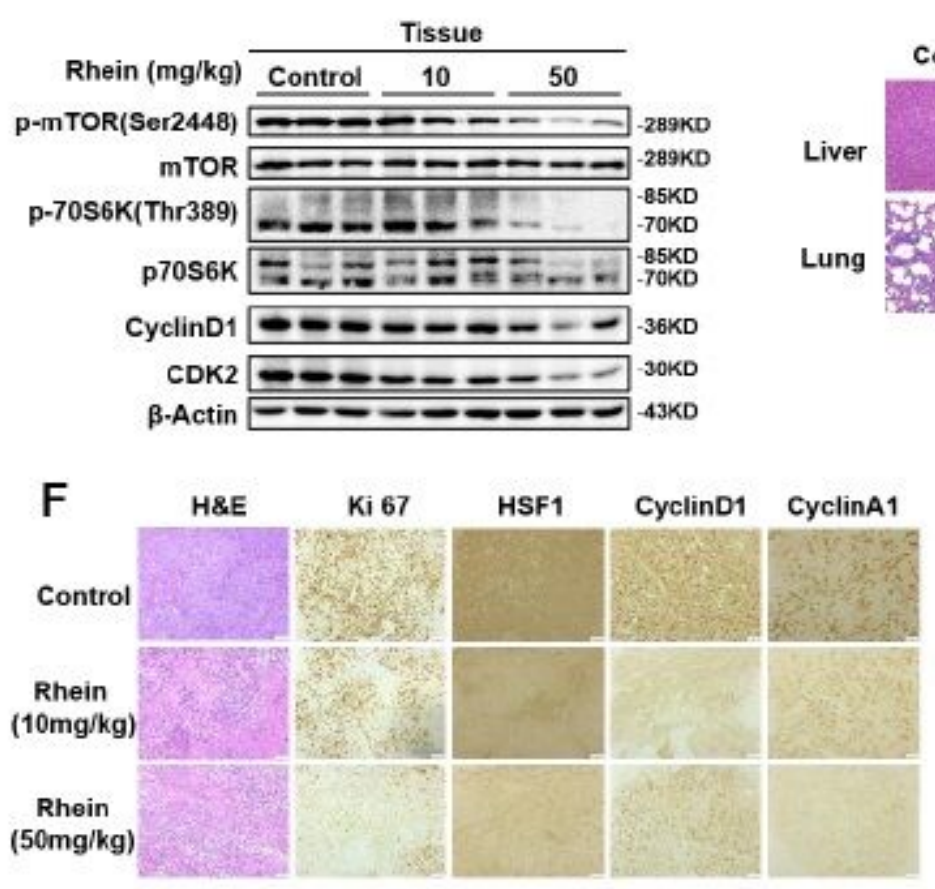

\section{G}

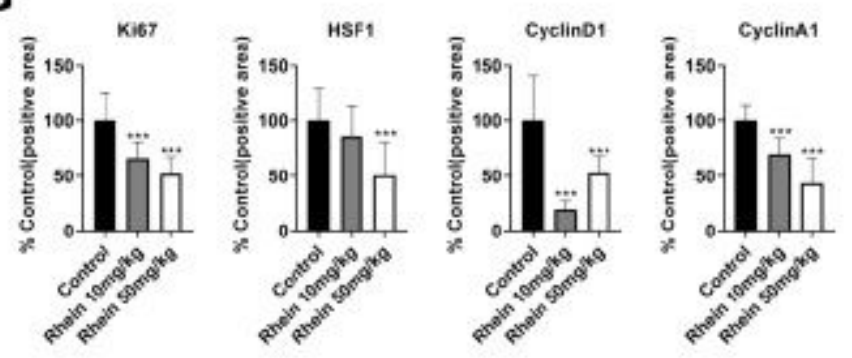

C

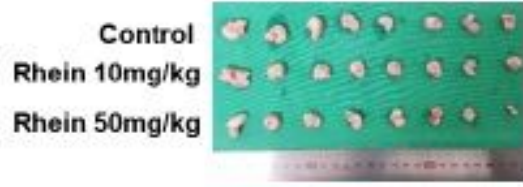

$E$

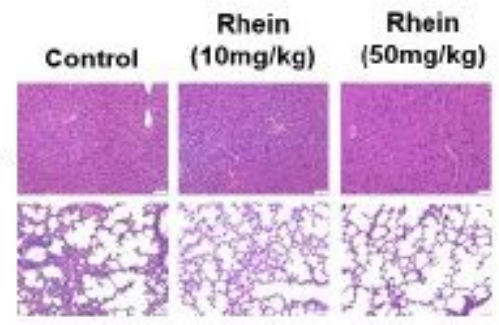

\section{H}
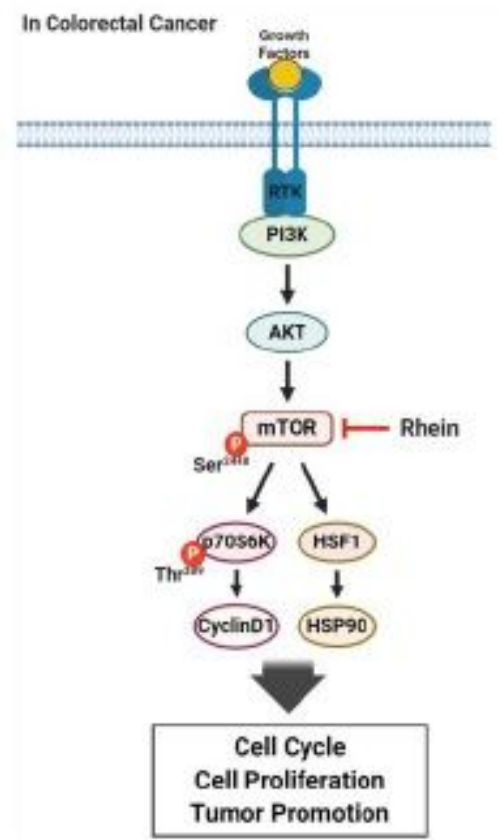

Figure 7

Rhein suppresses HCT116 CRC tumor growth in a xenograft mouse model. a Tumor volumes were plotted over 38 days after inoculation of cells. b Body weights. c The images presented tumors from mice treated 
with vehicle or rhein (10 or $50 \mathrm{mg} / \mathrm{kg}$ ). d The expressions of p-mTOR, mTOR, p-p70 S6K, p70S6K, Cyclin D1, CDK2 and $\beta$-Actin was detected by western blotting. e Histopathology conducted by H\&E staining of liver and lung samples. f-g, Immunohistochemistry staining analysis of Ki-67, HSF1, Cyclin D1 and Cyclin A1 in HCT116 xenograft tumors. h Schematic diagram of mechanism of action of rhein on this research. (magnification, 200x). ${ }^{*}<<0.05,{ }^{*} \mathrm{P}<0.01, * \star * \mathrm{P}<0.001$.

\section{Supplementary Files}

This is a list of supplementary files associated with this preprint. Click to download.

- AdditionalFigure1.jpg

- AdditionalFigure2.jpg 